American Journal of Applied Sciences 9 (5): 624-632, 2012

ISSN 1546-9239

(C) 2012 Science Publications

\title{
Multiresolution Analysis Based Effective Diagnosis of Induction Motors
}

\author{
${ }^{1,2}$ Houda Ben Attia Sethom and ${ }^{3}$ Mediha Ajjabi Ghedamsi, \\ ${ }^{1}$ Department of Electrical Engineering, University of Carthage, \\ Higher School of Technology and Data Processing (ESTI), Tunis, Tunisia \\ ${ }^{2}$ Department of Electrical Engineering, University of Tunis El Manar, \\ National School of Engineers of Tunis (ENIT), \\ Laboratory of Electrical Systems (LSE), Tunis, Tunisia \\ ${ }^{3}$ Department of Electronic, University of Carthage, \\ Higher Institute of Applied Sciences and Technology (ISSAT) of Mateur, Tunisia
}

\begin{abstract}
Problem statement: Effective detection and localization of unbalance voltage supply affecting an induction motor may be compromised in presence of additionnal noise. Approach: In order to overcome the non possibility of the default detection and localization in presence of noise, the use of the discrete wavelet transform and especially the MultiResolution Analysis algorithm, to remove efficiently the noise associated to the stator currents is proposed. Results: Simulation results show that the de-noised stator current is a good estimation of the non disturbed one. They show also that the default occurrence instant can be well detected starting from high frequency detail signal. Furthermore, the signal details which characterize the default are not smoothed and still characterize the default occurrence. Experimental results validate the de-noising approach efficiency and the effective unbalance detection considering the MRA technique. Conclusion: In this study, current signal denoising problem is studied in order to perform an effective detection of an unbalance voltage supply induction machine default. It can be deduced that the wavelet transform and particularly the MRA technique is a good and powerful solution for both non linear noise filtering and transient default detection. Both simulation and experimental results show clearly that the stator currents MRA allows not only to detect when the default appears but also helps to separate the useful signal from noise without affecting or suppressing the default transient information.
\end{abstract}

Key words: Induction motor, unbalance voltage, multiresolution analysis, non linear demising detection, transient information, simulation results, current signal demising, remove efficiently, noise filtering

\section{INTRODUCTION}

In industrial, production and manufacturing systems, voltage unbalance is one of the most defaults that affect electric machines, in particular induction machines which are an important component largely spread in industries. Many studies and researches were and continue to be carried out, since 1936 till now (Moussa et al., 2010; Chatchanayuenyong, 2009; Faiz et al., 2004), to show causes and effects of high unbalance voltage supply level on stator operating conditions and motor performances. In fact, unbalance level is considered to be a good indicator of the AC electric motors health.

Thus, voltage unbalance is due to several causes, such as (Moussa et al., 2010; Siddique et al., 2004):
- Single phase, two-phase or three-phase undervoltage unbalance

- Single phase, two-phase or three-phase overvoltage unbalance

- Unequal single phase angle or two phase angles displacement

- One phase load nearby the motor

- Unbalanced distribution of single-phase loads on the power system

- Single-phase to ground defaults

These induction motor functioning conditions may lead to many damages and performance reduction of the motor (Moussa et al., 2010; Chatchanayuenyong, 2009; Tallam et al., 2007; Siddique et al., 2004) which are: 
Am. J. Applied Sci., 9 (5): 624-632, 2012

- Motor currents unbalance: in this case the currents unbalance level is six to ten times that of voltage unbalance Therefore, stator currents are characterised by the increasing of the third and the fifth harmonics amplitude

- Increase in iron and copper losses

- Thermal overloading: in fact, a $3.5 \%$ voltage unbalance level per phase causes a winding temperature increase of $25 \%$ in the phase with the highest current

- Damage of bearings, laminations and winding insulation due to harmonics

- Torque ripples which cause motor vibrations and then important noise level and motors mechanical stresses

- Full load speed reduction and speed ripples

- Reactive power consumption increase

- Shorten life of motors: In fact, severe and repetitive over-voltage condition may cause short circuits and consequently breakdown of motors

Thus, to preserve the motor life and a larger margin of safety operating, efficient monitoring and early detection and localization of voltage supply unbalance should be provided in time and should be quite sensitive to the motor conditions in general and particularly to the stator conditions.

Many methods, widely studied in literature, have been adopted for the monitoring of electric motors and especially induction motors, as well as the diagnosis of their defaults such as artificial intelligence based methods (Kanthalakshmi and Manikandan, 2011; Prasannamoorthy and Devarajan, 2010; Bouzid et al., 2008; Martins et al., 2007; Tallam et al., 2007), signal processing based methods (Prasannamoorthy and Devarajan, 2010; Kia et al., 2007; Jung et al., 2006), automatic and control based methods (Kanthalakshmi and Manikandan, 2011; Angelo et al., 2009) and a combination of them (Prasannamoorthy and Devarajan, 2010).

One of the signal processing monitoring techniques which is largely used and promising is the wavelet technique and particularly the Multiresolution Analysis (MRA) which is a fast algorithm of the discrete wavelet decomposition technique. In fact, wavelet technique is a very useful, powerful and efficient tool for monitoring and diagnosis machines purpose because of its capabilities to perform signal content analysis in both time and frequency domains (Prasannamoorthy and Devarajan, 2010; Cusido et al., 2008; Ukil and Zivanovic, 2005; Truchetet and Laligant, 2004; Chow and Hai, 2004; Lee et al., 2004). This is of a great importance for the detection of changes starting from the motor signals and especially abrupt and time localised changes caused by defaults occurrence.
Since the monitoring and the diagnosis are performed from the motor signals measured from sensors, in any case, the sensors outputs include significant additional noise. The presence of noise complicates significantly effective data analysing and consequently default detection and localisation.

Noise reduction is mostly performed using filters such as low-pass filters or band-pass filters. However, these filters are useful only for removing noises in specific frequency ranges. Moreover, noise and especially the white noise contain components in all frequency ranges; it cannot be effectively removed by linear filtering. Thus, as demonstrated by Donoho (1995), Giaouris et al. (2008) and Ali et al. (2010), the discrete wavelet transform is used as a demising tool in order to overcome this limit and separate the useful signal from the noise. The advantage of this tool, such as proved in a previous work, is that the filtering will be performed without losing the useful information about the default occurrence instant.

In this study, early robust detection of an unbalance voltage affecting an induction motor is studied using the discrete wavelet technique. The default detection is carried out using stator currents. The accent is put on capabilities of the discrete wavelet technique to allow performing both the demonising of stator currents signals and a robust diagnosis of the default starting from the de-noised stator currents. White Gaussian noise is added to the simulated stator currents to reproduce experimental conditions. The robust detection of the default after signal demonising is simulated and validated experimentally.

This study is organized as follows. First, the Multiresolution Analysis Demising technique is introduced. Then, the whole procedure of default detection respectively from noisy stator currents (before denoising) and from de-noised stator currents (after denoising) is described and illustrated by simulation and experimental results in order to validate the study. Finally, these results are discussed to conclude to the effective diagnosis of the induction motor voltage unbalance and to the prospective of this study.

\section{MATERIALS AND METHODS}

MultiResolution Analysis Demising Technique: The MRA demonising procedure is based on the Discrete Wavelet Transform (DWT) principle.

As demonstrated by Mallat (1989), the decomposition of a numerical signal using DWT consists in applying a bank of filters to this signal. These filters are band-pass and low-pass filters with different bandwidths. 
Am. J. Applied Sci., 9 (5): 624-632, 2012

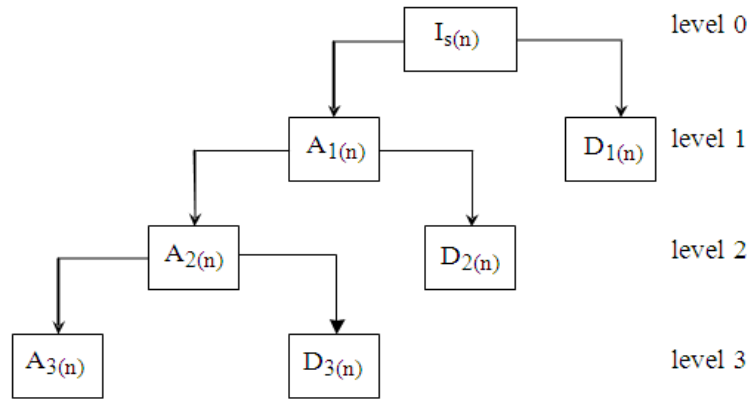

Fig. 1: Discrete wavelet transforms principle

Then, by applying the Mallat's MRA algorithm to a discrete-time current signal $\mathrm{I}_{\mathrm{s}}$ at the scale $\mathrm{J}$, this signal is decomposed into approximated signals noted $A_{1}, A_{2}$, ..., $\mathrm{A}_{\mathrm{J}}$ and into detailed signals noted $\mathrm{D}_{1}, \mathrm{D}_{2}, \ldots, \mathrm{D}_{\mathrm{J}}$. The approximated signals are the output of the low-pass filter bank whereas the detailed signals are the output of the high-pass filter bank Fig. 1.

The signal $I_{s}$ can then be reconstructed using the approximated and the detailed signals according to Eq. 1:

$$
\mathrm{I}_{\mathrm{s}}(\mathrm{n})=\mathrm{A}_{\mathrm{J}}(\mathrm{n})+\sum_{\mathrm{i}=1}^{\mathrm{J}} \mathrm{D}_{\mathrm{i}}(\mathrm{n})
$$

$\mathrm{A}_{\mathrm{J}(\mathrm{n})}$ is the product of the scaling coefficients $\alpha_{\mathrm{J}, \mathrm{p}}$ by the scaling function $\phi_{\mathrm{J}, \mathrm{p}}$ at level $\mathrm{J}$, defined as follows Eq. 2:

$$
\mathrm{A}_{\mathrm{J}}(\mathrm{n})=\sum_{\mathrm{p}=1}^{\mathrm{J}} \alpha_{\mathrm{J}, \mathrm{p}} \Phi_{\mathrm{J}, \mathrm{p}}(\mathrm{n})
$$

$D_{I(n)}$ is the product of the wavelet coefficients $\beta_{I, p}$ by the mother wavelet function $\Psi_{\mathrm{I}, \mathrm{p}}$ at each level I, defined as follows Eq. 3:

$$
\mathrm{D}_{\mathrm{I}}(\mathrm{n})=\sum_{\mathrm{p}=1}^{\mathrm{I}} \beta_{\mathrm{I}, \mathrm{p}} \Psi_{\mathrm{I}, \mathrm{p}}(\mathrm{n})
$$

The maximum level decomposition, noted $\mathrm{J}_{\mathrm{Max}}$, depends on the samples number $\mathrm{N}$ of the signal $\mathrm{I}_{\mathrm{s}}$ to be decomposed, according to the condition Eq. 4:

$$
2^{\mathrm{J}_{\mathrm{Max}}}<\mathrm{N}
$$

If the signal $\mathrm{I}_{\mathrm{s}}$ is contaminated by a noise, then the MRA denoising technique, based on the described MRA algorithm, consists in the three following steps, as established by Donoho (1995).

Step 1: Signal decomposition: This step requires an appropriate wavelet type and wavelet decomposition level M. The wavelet chosen will be applied to the noisy signal, noted $\mathrm{I}_{\mathrm{sn}}$, so as to determine the noisy wavelet coefficients from the first level to the $\mathrm{M}^{\text {th }}$ level.

Step 2 :Thresholding: This step consists first in the selection of appropriate threshold limits and second in the smoothing of the detailed signals by applying the selected thresholds.

Step 3 : Signal reconstruction: This step consists in application of the inverse wavelet transform to threshold wavelet coefficients, by using a low frequency approximation of the $\mathbf{M}^{\text {th }}$ level and the smoothed details from the first level to the $\mathrm{M}^{\text {th }}$ level, to obtain a de-noised signal, noted $\mathrm{I}_{\mathrm{sd}}$.

Thus, the signal $\mathrm{I}_{\mathrm{sd}}$ represents an estimation of the signal $\mathrm{I}_{\mathrm{s}}$

In order to perform robust default detection against noise, the MRA demonising technique implementation requires choosing carefully the mother wavelet type and order, the decomposition level, threshold limits, the threshold method and the noise model. Mat lab environment has been used to configure the parameters set to process the MRA demonising steps as following:

- Mother Wavelet Type and Order: The mother wavelet and its order should be carefully selected, so as to obtain the better approximation of the original signal $\mathrm{I}_{\mathrm{sd}}$ starting from the noisy signal $\mathrm{I}_{\mathrm{sn}}$. In fact, the mother wavelet type and order determine how well the original signal is estimated

- Decomposition Level : As the wavelet transform is performed, at most, for $\mathrm{J}_{\mathrm{Max}}$ levels and the noise appears with significant amplitude at $\mathrm{M}$ detail signals, with $\mathrm{M} \leq \mathrm{J}_{\mathrm{Max}}$, so to reduce noise from these contaminated $\mathrm{M}$ levels, then the noisy signal can be decomposed at only $\mathrm{M}$ levels

- Threshold Limits: The choice of the threshold limits for each level I depends on the noise type. Many methods for setting the threshold limits have been proposed. Donoho and Johnston propose the following thresholds:

- Fixed from threshold": The threshold is usually named "universal threshold". It depends on the estimated noise power

- Rigorous Sure": The threshold is based on Stein's Unbiased Risk Estimate

- Heuristic Sure": The threshold is chosen using a combination of the previous two methods. As a result, if the SNR (Signal to Noise Ratio) is very small, the "Fixed form threshold" method is used. In the other case, the "Rigorous Sure" threshold is applied

- Minimax": The threshold is chosen to yield minima performance for the mean square error 


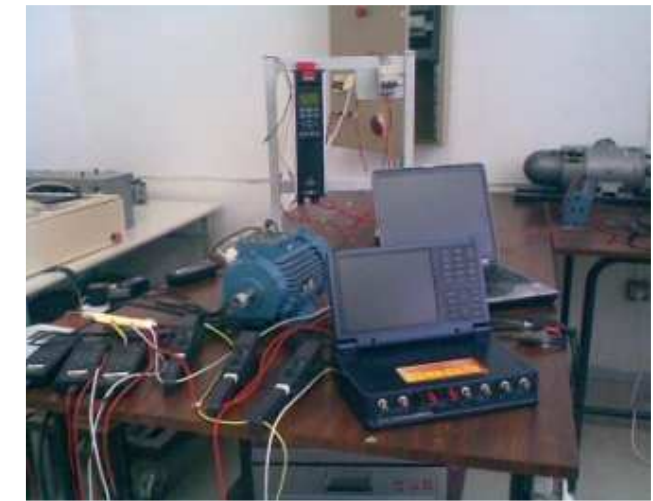

Data acquisition

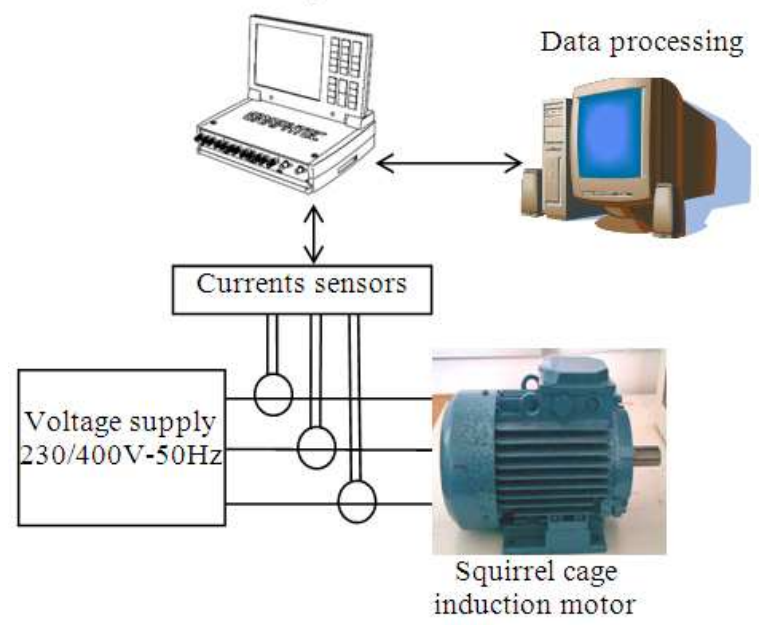

Fig. 2: Experimental setup

Threshold method: There are two most popular threshold methods:

- Hard Thresholding: All wavelet coefficients, whose absolute value is less than the specified threshold limit, are set to zero. The other wavelet coefficients are maintained at their values

- Soft Thresholding: All wavelet coefficients whose absolute value is less than the specified threshold limit are set to zero. The other wavelet coefficients are attenuated by the threshold value

Noise model: The noise added to the considered signal can be modelled as:

- A scaled white noise.

- An unscaled white noise.

- A non-white noise.

The Multiresolution Analysis denoising technique has been applied, in a previous work, to the diagnosis of an inter-turn short-circuits in an induction motor and has given very good and promising results. In this study, the same procedure will be applied to the detection of an unbalance voltage supply occurrence affecting an induction motor.

Experimental setup: A photo and a block diagram of the experimental setup are depicted in Fig. 2. The characteristics of the squirrel cage induction motor, that has been used to carry out experiments, are given as following:

- $\quad$ Rated power: $1,5 \mathrm{~kW}$

- Rated voltage supply: 230/400V

- $\quad$ Rated stator currents: 6.23/3.6A

- Rated speed: $1400 \mathrm{rpm}$

Stator currents acquisition has been realised thanks to the acquisition station GRAPHTEC DM3000.

The motor operating has been considered with $4.6 \%$ over-voltage level affecting the voltage supply of the motor.

This unbalance voltage level has been obtained by inserting a single-phase resistive load between the supply and the induction motor.

\section{RESULTS}

Simulation results: Simulations have been carried out in order to reproduce respectively $5 \%$ under-voltage and $5 \%$ over-voltage levels affecting the induction motor phase a voltage supply, as shown by Fig. 3 and 4 . This unbalance level should not be reached according to the standard NEMA which recommends a maximum of $1 \%$ unbalanced voltage for AC electric motors.

To study the noise effect on the default detection and localisation efficiency, different simulations have been carried out in the following conditions:

- Default detection from stator current $\mathrm{I}_{\mathrm{sa}}$ without added noise

- Default detection from noisy stator current $\mathrm{I}_{\mathrm{san}}$, where

- $\mathrm{I}_{\mathrm{san}}=\mathrm{I}_{\mathrm{sa}}+\mathrm{I}_{\mathrm{n}}$ and $\mathrm{I}_{\mathrm{n}}$ is the noise which contaminates $\mathrm{I}_{\mathrm{s}}$

- Default detection from de-noised stator current $\mathrm{I}_{\mathrm{sad}}$, where $I_{\text {sad }}$ is the result of the $I_{\text {san }}$ MRA demonising

In each of these three cases, the stator current sequences being studied are:

- The steady state induction motor operation in absence of voltage unbalance (before default occurrence)

- The voltage unbalance transient occurrence

- The steady state induction motor operation in presence of voltage unbalance (after default occurrence) 


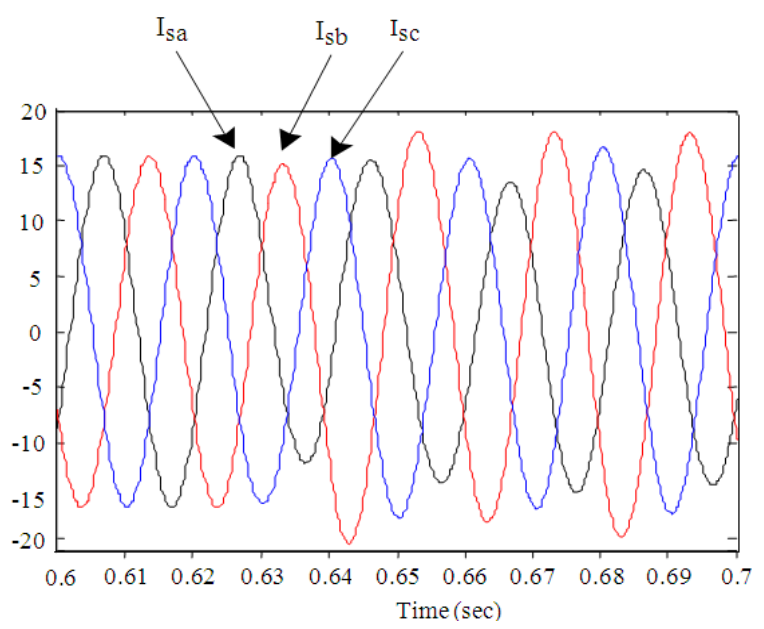

Fig. 3: 5\% under-voltage affecting the motor phase "a" voltage supply

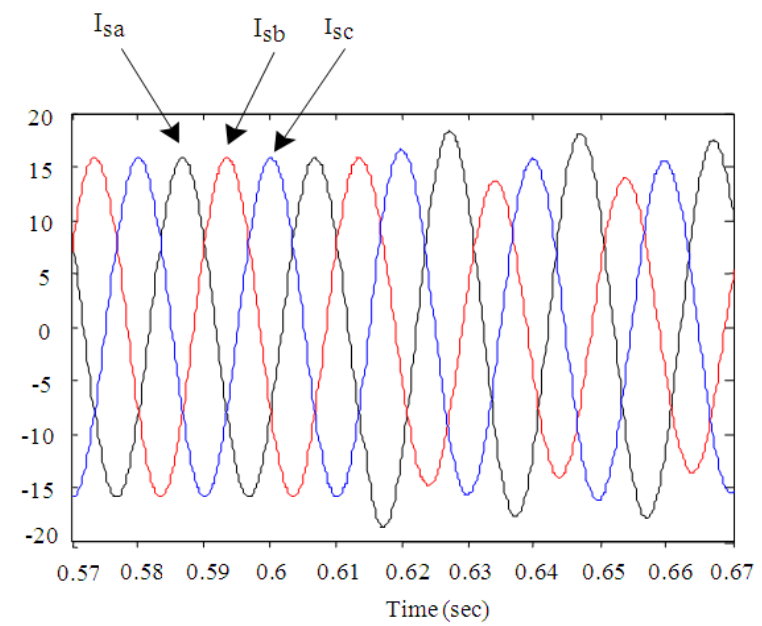

Fig. 4: 5\% over-voltage affecting the motor phase "a" voltage supply

Table 1: Frequency bands obtained for 6 levels wavelet decomposition

\begin{tabular}{ll}
\hline Signal & Related frequency band \\
\hline $\mathrm{A}_{6}$ & $0-78.125 \mathrm{HZ}$ \\
$\mathrm{D}_{6}$ & $78.125-156.25 \mathrm{HZ}$ \\
$\mathrm{D}_{5}$ & $156.25-312.5 \mathrm{HZ}$ \\
$\mathrm{D}_{4}$ & $312.5-625 \mathrm{HZ}$ \\
$\mathrm{D}_{3}$ & $625-1250 \mathrm{HZ}$ \\
$\mathrm{D}_{2}$ & $1.25-2.5 \mathrm{kHZ}$ \\
$\mathrm{D}_{1}$ & $2.5-5 \mathrm{kHZ}$ \\
\hline
\end{tabular}

It will be considered that the induction motor stator currents are affected with white Gaussian noise, where the SNR was fixed with regard to the experimental conditions. To perform default detection, the stator currents are sampled at $10 \mathrm{kHz}-$ rate and then decomposed at 6 levels, which is sufficient to highlight the default occurrence.

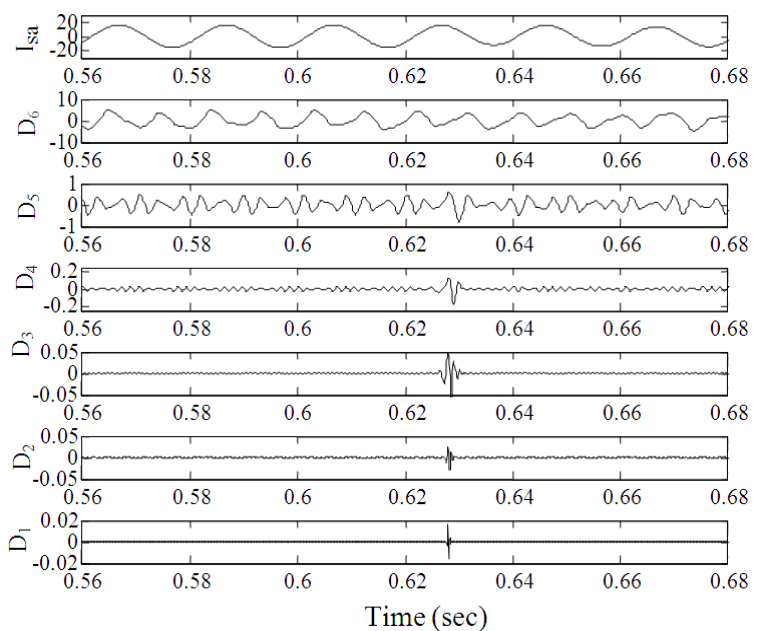

Fig. 5: MRA of $\mathrm{I}_{\mathrm{sa}}$ using DB4, $\mathrm{J}=6$. Case of $5 \%$ undervoltage affecting the motor phase "a" voltage supply

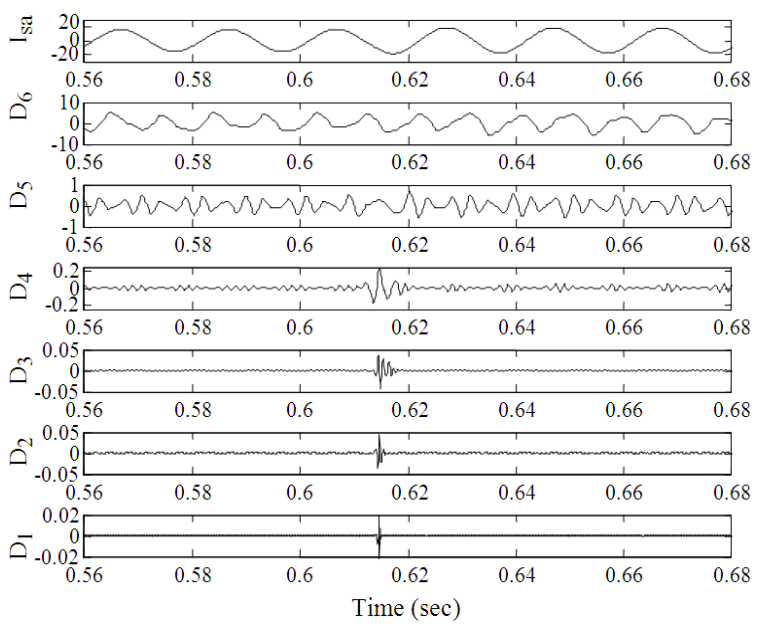

Fig. 6: MRA of $\mathrm{I}_{\mathrm{sa}}$ using DB4, $\mathrm{J}=6$. Case of $5 \%$ over-voltage affecting the motor phase "a" voltage supply

Daubechies is used as a mother wavelet because this wavelet family gives very satisfactory results for detecting transient phenomena, as demonstrated in previous works. To select the optimal mother wavelet order, several trials have been carried out. The Daubechies order 4-mother wavelet, noted DB4, has been retained for performing the signal multiresolution analysis.

The frequency bands related to the 6-levels wavelet decomposition are displayed in the Table 1.

Default detection from non noisy stator currents: The results related to the stator current signal $I_{\mathrm{sa}}$ decomposition in case of 5\% under-voltage and 5\% overvoltage are shown respectively in Fig. 5 and 6. 
Am. J. Applied Sci., 9 (5): 624-632, 2012

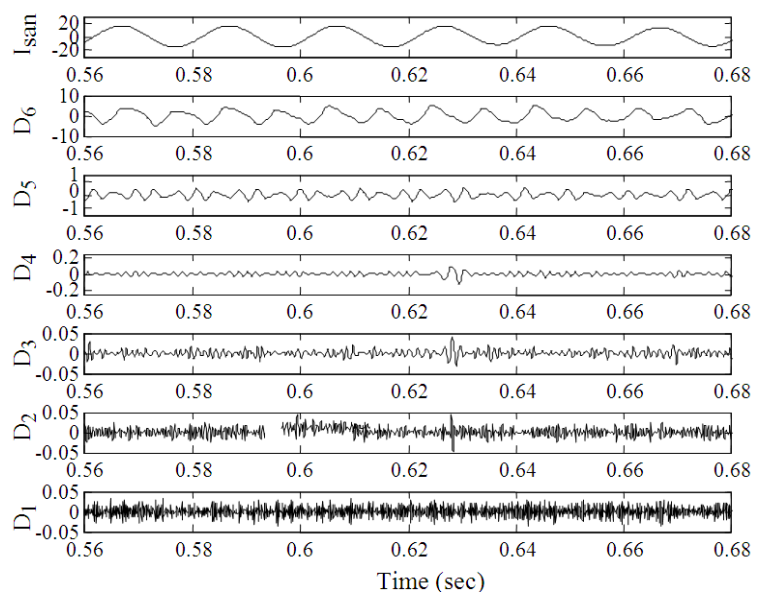

Fig. 7: MRA of $\mathrm{I}_{\text {san }}$ using DB4, $\mathrm{J}=6$. Case of $5 \%$ undervoltage affecting the motor phase "a" voltage supply

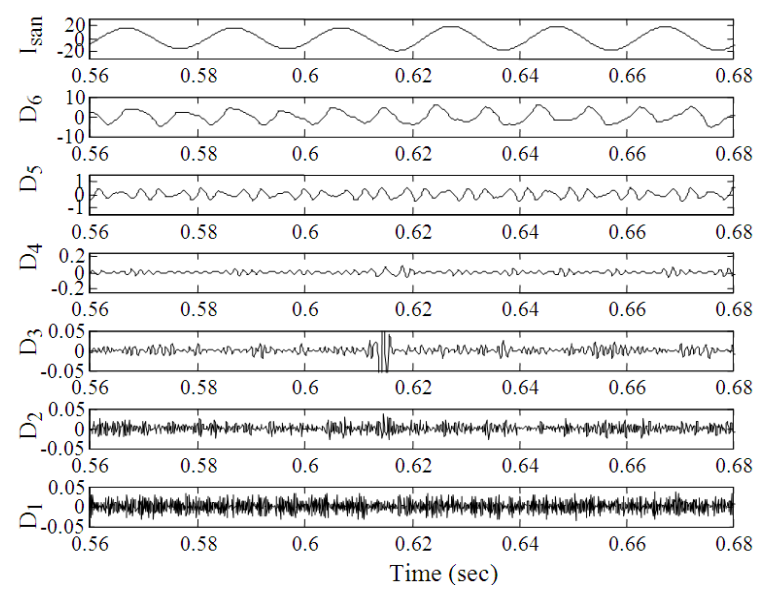

Fig. 8: MRA of $\mathrm{I}_{\text {san }}$ using DB4, $\mathrm{J}=6$. Case of $5 \%$ overvoltage affecting the motor phase "a" voltage supply

This decomposition, so realized, allows the monitoring of the default frequency components $150 \mathrm{~Hz}$ and $250 \mathrm{~Hz}$ (for a $50 \mathrm{~Hz}$ supplied motor), which characterize the unbalance voltage default, in a separate frequency areas.

In fact, the frequency component $150 \mathrm{~Hz}$ belongs to the sub-band $[78,125 \mathrm{~Hz}-156,25 \mathrm{~Hz}]$ related to D6 and $250 \mathrm{~Hz}$ belongs to the sub-band $[156,25 \mathrm{~Hz}-312,5 \mathrm{~Hz}]$ related to D5.

Default detection from noisy stator currents: The noisy signal $I_{\text {san }}$ and its MRA decomposition are represented in Fig. 7 and 8 respectively for the case of $5 \%$ under-voltage and 5\% over-voltage. The six levels detailed signals are denoted respectively D6, ..., D1.

Furthermore, Fig. 9 gives the MRA decomposition of only the white Gaussian noise $I_{n}$.

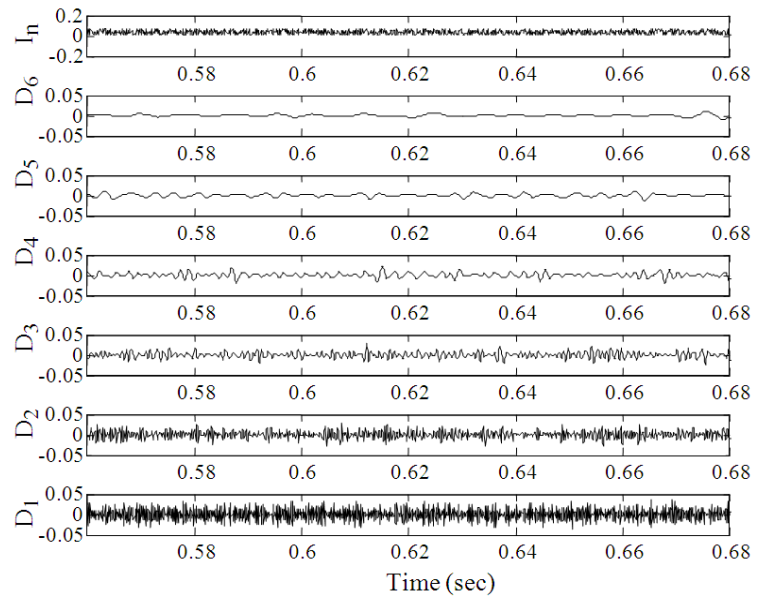

Fig. 9: MRA of the white Gaussian noise using DB4, $J=6$

Default detection from de-noised stator currents: In order to de-noise the stator current signal $I_{\text {san }}$ which contains the default transient, the following parameters have been considered:

- $\quad$ Number of decomposition level: 4-level wavelet used for the signal demonising is sufficient because only detail signals D1, D2, D3 and D4 need to be filtered.

- Noise Model: The unsealed white noise corresponds to the noise type initially added to $\mathrm{I}_{\mathrm{sa}}$

- Threshold method: The soft thresholding provides smoother results than the hard thresholding technique and has been retained for the stator current wavelet demonising

- Mother wavelet: When too high order mother wavelet is chosen, the signal obtained after demonising becomes smoother and transient cannot be detected. For this reason and after several trials, the DB3 mother wavelet has been considered to decompose the noisy signal

- Threshold limits: all the methods allow removing the noise efficiently. Only the «Rigorous Sure» had permitted to recover correctly the transient

- According to the Donoho-Johnstone approach, the following steps have been applied to the signal $\mathrm{I}_{\text {san }}$ in order to obtain the filtered signal $\mathrm{I}_{\mathrm{sad}}$

- Decomposing the signal $\mathrm{I}_{\text {san }}$ into approximation A4 and detail sub-bands D1, D2, D3 and D4

- Thresholding detail coefficients of the obtained signals D1, D2, D3 and D4 from the previous decomposition in order to obtain the filtered detail signals

- Applying the inverse wavelet transform to reconstruct a better estimation of the original signal from approximation signal A4 and filtered detail signals D1, D2, D3 and D4 
Am. J. Applied Sci., 9 (5): 624-632, 2012

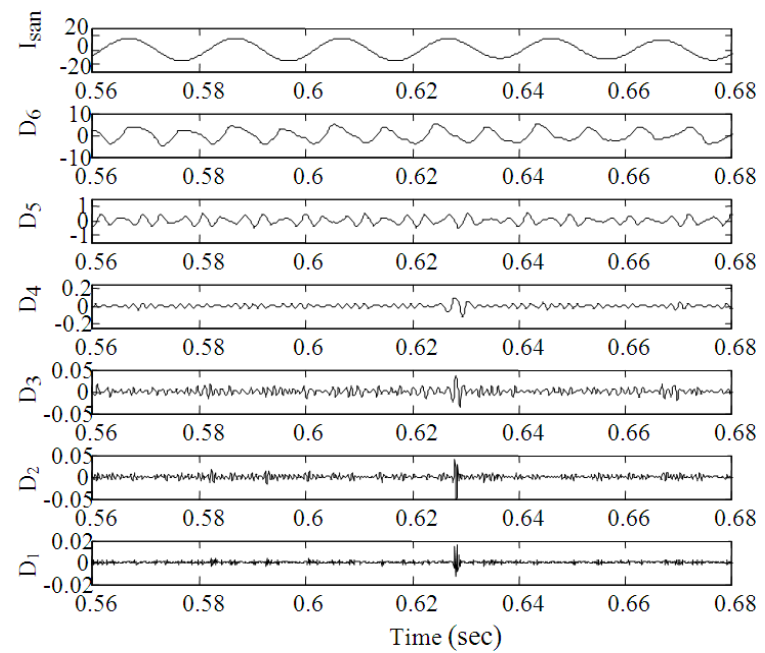

Fig. 10: MRA of de-noised signals $\mathrm{I}_{\text {sad }}$. Case of $5 \%$ under-voltage affecting the motor phase "a" voltage supply

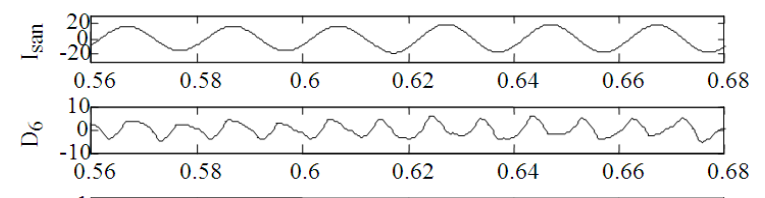

㲅

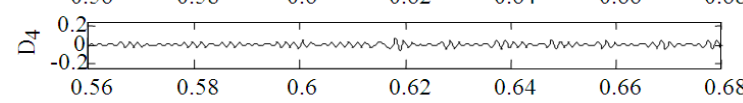

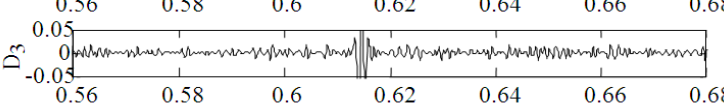

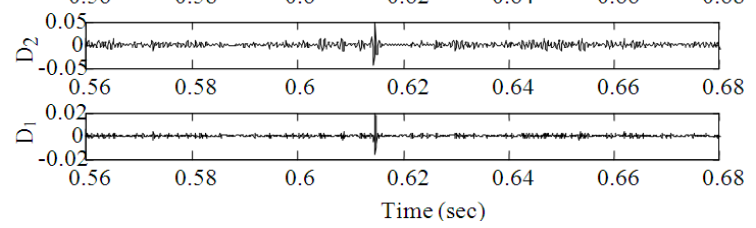

Fig. 11: MRA of de-noised signals $\mathrm{I}_{\mathrm{sad}}$. Case of $5 \%$ over-voltage affecting the motor phase "a" voltage supply

Hence, only D1, D2, D3 and D4 signal details are threshold, because the frequency band of the noise elimination extends from $312,5 \mathrm{~Hz}-5 \mathrm{kH}$. As A4 = A6+D5+D6, then the sub-bands related to level 5 and 6 detailed signals, which contain frequencies related to the default, are included in the approximation signal A4 and are not smoothed. Therefore, the reconstructed signal after thresholding details preserve the main information about the default.

In order to detect the default occurrence instant, the demonising signal $\mathrm{I}_{\mathrm{sad}}$ is decomposed again in 6 levels.

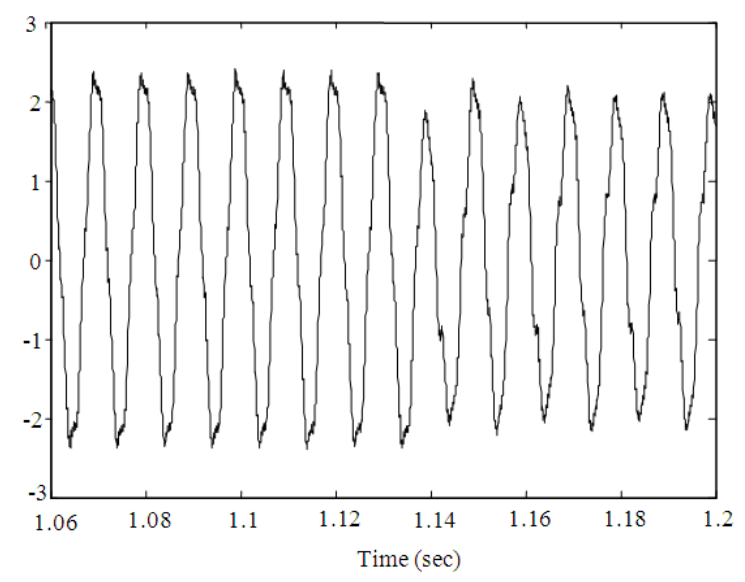

Fig. 12: Stator current of phase "a" before and after applying a $4.6 \%$ over-voltage unbalanced supply

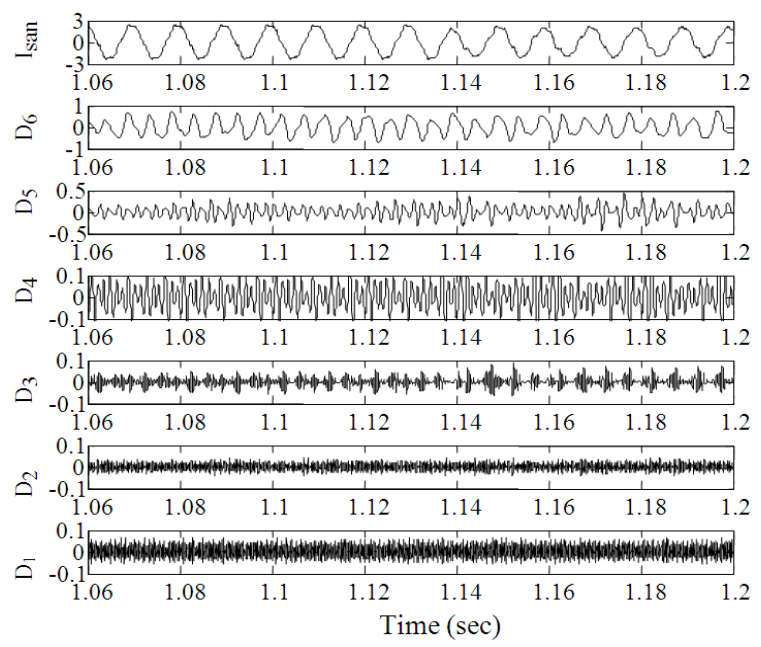

Fig. 13: Stator current of phase "a" and its MRA decomposition before denoising

The wavelet mother is still DB4. The decomposition results are shown in Fig. 10 and 11.

Experimental results: The induction motor stator currents demonising and the unbalance voltage occurrence detection after demonising have been performed considering the approach protocol described in this study.

Figure 12 presents the induction motor stator current after applying arbitrarily a $4.6 \%$ over-voltage unbalance on the motor supply.

Figures 13 and 14 show respectively the decomposition of the experimental stator current before and after denoising it, according to the same steps considered for the simulation results and described above. 
Am. J. Applied Sci., 9 (5): 624-632, 2012

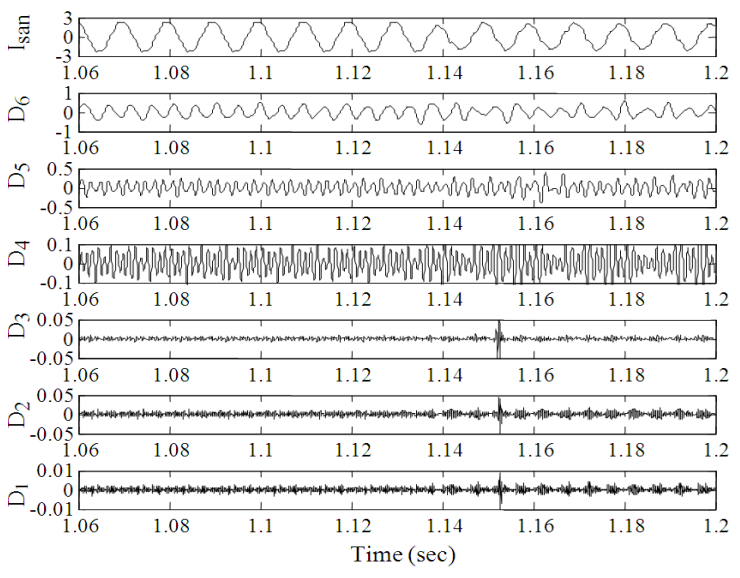

Fig. 14: Stator current of phase "a" and its MRA decomposition after demising

\section{DISCUSSION}

As shown by Fig. 5 and 6, which correspond to simulation results related to the non noisy stator current signal $\mathrm{I}_{\mathrm{sa}}$ decomposition and considering the detail signals $\mathrm{D}_{1}, \mathrm{D}_{2}, \mathrm{D}_{3}$ and $\mathrm{D}_{4}$, high frequency transient signals are highlighted and then transient instant can be well determined. This instant corresponds to the appearance instant of the unbalance supply in the motor.

However, as shown by Fig. 7 and 8, which correspond to simulation results related to the noisy stator current signal $I_{\text {san }}$ decomposition, the fault transient is blurred by the noise and cannot be detected anymore. In addition, the noise amplitude is more significant in sub-bands $\mathrm{D}_{1}, \mathrm{D}_{2}, \mathrm{D}_{3}$ and $\mathrm{D}_{4}$ than in subbands $\mathrm{D}_{5}$ and $\mathrm{D}_{6}$. Then, only signal details $\mathrm{D}_{1}, \mathrm{D}_{2}, \mathrm{D}_{3}$ and $\mathrm{D}_{4}$ are de-noised to improve transient detection.

Furthermore, the Gaussian noise decomposition, given by Fig. 9, shows that the noise does not present the same behaviour in each sub-band detail. In fact, the noise power is divided by a factor of two in each frequency band.

Finally, the de-noised stator currents decompositions, given by Fig. 10 and 11, show that the default transient detection become possible after the non linear denoising procedure:

In summary, by comparing Fig. 5 and 10 (case of 5\% under-voltage) and Fig. 6 and 11 (case of 5\% overvoltage), it can be well noted that:

- The de-noised signal is a good estimation of the non disturbed signal

- The default occurrence instant can be well detected starting from detail signal D1

- The signal details at level 5 and 6, which characterize the default, are not smoothed and still characterize the default occurrence
Finally, the decompositions obtained from the experimental stator currents confirm the simulation results.

In fact, as it can be well noted from Fig. 13, the presence of noise does not allow detecting any change in the stator current and blurs completely the default occurrence.

However, Fig. 14 shows clearly that the stator current denoising helps to remove efficiently noise from the processed signal and then to obtain effectively an estimation of the original signal without affecting the default transient information.

Then, experimental results confirm the efficiency of the demonising technique and validate the monitoring and the diagnosis approach presented in this study.

\section{CONCLUSION}

In this study, current signal demonising problem is studied in order to perform an effective detection of an unbalance voltage supply induction machine default. It can be deduced that the wavelet transform and particularly the MRA technique is a good and powerful solution for both noise filtering and transient default detection. Both simulation and experimental results show clearly that the stator current MRA allows not only to detect when the default appears but also helps to separate the useful signal from noise without affecting or suppressing the transient default information.

\section{ACKNOWLEDGMENT}

This research project was supported by the Tunisian Ministry of High Education and Scientific Research.

\section{REFERENCES}

Ali, A.D., P.D. Swami and J. Singhai, 2010. Modified Curvelet Thresholding Algorithm for Image Denoising. J. Comput. Sci., 6: 18-23. DOI: 10.3844/jcssp.2010.18.23

Angelo, C.H.D., G.R. Bossio, S.J. Giaccone, M.I. Valla and J.A. Solsona et al., 2009. Online model-based stator-fault detection and identification in induction motors. IEEE Trans. Industrial Elect., 56: 46714680. DOI: 10.1109/TIE.2009.2012468

Bouzid, M., G. Champenois, N.M. Bellaaj, L. Signac and K. Jelassi, 2008. An effective neural approach for the automatic location of stator interturn faults in induction motor. IEEE Trans. Industrial Elect., 55: 4277-4289. DOI: 10.1109/TIE.2008.2004667 
Chatchanayuenyong, T., 2009. A fast series active filter using sliding mode control to correct and regulate unbalance voltage in three-phase system. Am. J. Eng. Applied Sci., 2: 393-398. DOI: 10.3844/ajeassp.2009.393.398

Chow, T.W.S. and S. Hai, 2004. Induction machine fault diagnostic analysis with wavelet technique. IEEE Trans. Industrial Elect., 51: 558-565. DOI: 10.1109/TIE.2004.825325

Cusido, J., L. Romeral, J.A. Ortega, J.A. Rosero and A.G. Espinosa, 2008. Fault detection in induction machines using power spectral density in wavelet decomposition. IEEE Trans. Industrial Elect., 55: 633-643. DOI: 10.1109/TIE.2007.911960

Donoho, D.L., 1995. De-noising by soft-thresholding. IEEE Trans. Inform. Theory, 41: 613-627. DOI: 10.1109/18.382009

Faiz, J., H. Ebrahimpour and P. Pillay, 2004. Influence of unbalanced voltage on the steady-state performance of a three-phase squirrel-cage induction motor. IEEE Trans. Energy Conversion, 19: 657-662. DOI: 10.1109/TEC.2004.837283

Giaouris, D., J.W. Finch, O.C. Ferreira, R.M. Kennel and G.M. El-Murr, 2008. Wavelet denoising for electric drives. IEEE Trans. Industrial Elect., 55: 543-550. DOI: 10.1109/TIE.2007.911943

Jung, J.H., J.J. Lee and B.H. Kwon, 2006. Online diagnosis of induction motors using MCSA. IEEE Trans. Industrial Elect., 53: 1842-1852. DOI: 10.1109/TIE.2006.885131

Kanthalakshmi S. and V. Manikandan, 2011. Fault tolerant control using proportional-integralderivative controller tuned by genetic algorithm. J. Comput. Sci., 7: 1187-1193. DOI: 10.3844/jcssp.2011.1187.1193

Kia, S.H., H. Henao and G.A. Capolino, 2007. Digital signal processing for induction machines diagnosis - A review. Proceedings of the IEEE International Conference of Industrial Electronics Society IECON, Nov. 5-8, IEEE Xplore Press, Taipei, pp: 1155-1162. DOI: 10.1109/IECON.2007.4460325

Lee, S.H., S. Kim, J.M. Kim and M.H. Lee, 2004. Fourier and wavelet transformations for the fault detection of induction motor with stator current. Proceedings of the IEEE International Industrial Electronics Society IECON, Nov. 2-6, IEEE Xplore Press, 1: 383-388. DOI: 10.1109/IECON.2004.1433341
Mallat, S.G., 1989. A theory for multiresolution signal decomposition: The wavelet representation. IEEE Trans. Patt. Anal. Mach. Intell., 11: 674-693. DOI: 10.1109/34.192463

Martins, J.F., V.F. Pires and A.J. Pires, 2007. Unsupervised neural-network-based algorithm for an on-line diagnosis of three-phase induction motor stator fault. IEEE Trans. Industrial Elect., 54: 259264. DOI: 10.1109/TIE.2006.888790

Moussa, A.M., T.I. El-Shennawy, M.A. El-Gammal and A.Y. Abou-Ghazala, 2010. A dynamic voltage restorer for voltage sag mitigation in a refinery with induction motors loads. Am. J. Eng. Applied Sci., 3: 144-151. DOI: 10.3844/ajeassp.2010.144.151

Prasannamoorthy, V. and N. Devarajan, 2010. Fault detection and classification in power electronic circuits using wavelet transform and neural network. J. Comput. Sci., 7: 95-100. DOI: 10.3844/jcssp.2010.95.100

Siddique, A., G.S. Yadava and B. Singh, 2004. Effects of voltage unbalance on induction motors. Proceedings of the IEEE International Symposium on Electrical Insulation, Sept. 19-22, IEEE Xplore Press, pp: 26-29. DOI: 10.1109/ELINSL.2004.1380430

Tallam, R.M., S.B. Lee, G.C. Stone, G.B. Kliman and J. Yoo et al., 2007. A survey of methods for detection of stator-related faults in induction machines. IEEE Industry Appli. Mag., 43: 920-933. DOI: 10.1109/TIA.2007.900448

Truchetet, F. and O. Laligant, 2004. Wavelets in industrial applications: A review. Proc. SPIE. DOI: 10.1117/12.580395

Ukil, A. and R. Zivanovic, 2005. Abrupt change detection in power system fault analysis using wavelet transform. Proceedings of the International Conference on Power Systems Transients, Jun. 1923, Montreal, Canada, pp: 1-6. 